\title{
Pregnancy related acute kidney injury: nondialytic management
}

\author{
Kaliki Hymavathi Reddy ${ }^{1}$, K. Praveen Kumar ${ }^{2}$, Keerthi Rajan ${ }^{1}$, Sabreen Shaik ${ }^{1}$
}

\author{
${ }^{1}$ Department of Obstetrics \& Gynaecology, Narayana Medical College Hospital, Nellore-524002, A.P., India \\ ${ }^{2}$ Department of Nephrology, Narayana Medical College Hospital, Nellore-524002, A.P., India
}

Received: 14 January 2015

Accepted: 13 February 2015

\author{
*Correspondence: \\ Dr. Kaliki Hymavathi Reddy, \\ E-mail: drhymakrreddy@yahoo.co.in
}

Copyright: (C) the author(s), publisher and licensee Medip Academy. This is an open-access article distributed under the terms of the Creative Commons Attribution Non-Commercial License, which permits unrestricted non-commercial use, distribution, and reproduction in any medium, provided the original work is properly cited.

\begin{abstract}
Acute Kidney Injury (AKI) is associated with increased mortality and morbidity unless timely diagnosed \& promptly managed. An understanding of the renal physiologic changes that occur during pregnancy is essential for Proper evaluation, diagnosis, and management of Pregnancy Related AKI (PRAKI). In the general population, AKI can occur from prerenal, intrinsic/renal, and post-renal causes. Major causes of pre-renal azotemia include hyperemesis gravidarum and uterine hemorrhage in the setting of placental abruption. Intrinsic etiologies include infections from acute pyelonephritis and septic abortion, bilateral cortical necrosis, and acute tubular necrosis. Particular attention should be paid to specific conditions that lead to AKI during the second and third trimesters, such as preeclampsia, HELLP syndrome, acute fatty liver of pregnancy, and TTP-HUS. An understanding of the various etiologies of AKI in the pregnant patient is key to the appropriate clinical management \& prevention of adverse maternal/fetal outcomes. Sometimes PRAKI may require intensive management and even dialysis adding additional economical burden to the patient. We here, with report an interesting case of PRAKI diagnosed \& managed in time by simple medical measures thus delivering an effective treatment at a much lesser cost.
\end{abstract}

Keywords: Pregnancy, Preeclampsia, Acute kidney injury

\section{INTRODUCTION}

Acute Kidney Injury (AKI) is a rare but life threatening complication of pregnancy. The incidence has sharply declined from $0.5 / 1000$ to $1 / 20000$ births in developed countries. Pregnancy is still responsible for about $15-20 \%$ of AKI in developing countries.

Currently, maternal mortality due to Pregnancy Related Acute Kidney Injury (PRAKI) represents less than $10 \%$ in Europe and North America but remains high in the developing countries. Recent studies in India have shown a related maternal mortality rate of around $20 \%$.

We report an interesting case of preeclampsia causing acute kidney injury but could be successfully managed by simple medical means.

\section{CASE REPORT}

A 19 year old unbooked primigravida of term gestation with severe Preeclampsia had attended the antenatal OPD of Narayana medical college hospital - a tertiary care center with $\mathrm{C} / \mathrm{o}$ pain abdomen and watery discharge per vaginum since 2 days. She was not having regular antenatal check-ups anywhere.

\section{Clinical examination}

She was obese. BMI: 27.7; Puffiness of face+; Pedal oedema + . BP - 160/110 mmHg. Systemic examination: Heart and Lungs - NAD. Abdominal examination: Uterus term, acting 25-30 sec/4-5mts., cephalic Pr. FHR: variable $100-110 / \mathrm{mt}$. Per vaginal exam: Cervix 50-60\% effaced, $1 \mathrm{~cm}$ dilated, PP at -2 membranes absent. Thick meconium +. NST: With late decelerations. 


\section{Investigations}

Baseline investigations: WNL; PIH profile: WNL except Sr. creatinine value $1.1 \mathrm{mg} \%$; CUE: Proteinuria $3+$.

USG (Obstetrics): A single live fetus corresponding to gestational age 39 weeks +2 days in cephalic presentation; Liquor - very scanty; Placenta - fundal, Grade III. EFW: $2.8 \mathrm{~kg}$. No obvious congenital anomalies could be made out due to very scanty liq.

USG maternal abdomen: hyperechoeic areas present in the renal cortex with renal parenchymal changes. No evidence of ascites.

\section{Diagnosis}

19 year aged primigravida-term gestation - Severe preeclampsia-early labour-fetal distress.

\section{Management}

Case admitted to High Dependency Unit (HDU). Emergency L.S.C.S was done. Indication was being severe preeclampsia with fetal distress. Delivered a live female - wt. $2.8 \mathrm{~kg}$, APGAR 5-6-8. No intraoperative problems. Case shifted to postoperative HDU.

Immediate post-operative period: Marked oliguria noticed (Urine output $<15 \mathrm{ml}$ for 6 hours despite parenteral fluids ${ }^{@} 125 \mathrm{ml} /$ hour. Nephrology consultation done. Adv: Sr. creatinine \& Sr. albumin. The reports were $2 \mathrm{mg} \%$ (Preoperative Sr. creatinine $1.1 \mathrm{mg} \%$ ) \& 2.0g/l. respectively. Nephrologist advised 20\% human. Albumin infusion followed by inj. Lasix $40 \mathrm{mg}$ iv. Following this treatment amazingly there was found progressive improvement in the urine output (UOP). Pre albumin infusion UOP for 6 hours $<15 \mathrm{ml} \&$ post albumin infusion UOP for 6 hours $>350 \mathrm{ml}$. Repeat, $\mathrm{Sr}$. creatinine $1.3 \mathrm{mg} \%$ \& Sr. albumin $2.5 \mathrm{~g} / \mathrm{l}$. Following this four units of Fresh Frozen Plasma (FFP) given as per nephrologist's advice. Patient's recovery was satisfactory thereafter.

\section{DISCUSSION}

Acute Kidney Injury (AKI) occurs in response to a large number of pathophysiologic influences and is characterized by damage to one or more parts of the nephron with adverse functional consequences. It is increasingly recognized that even milder forms of dysfunction may have adverse effects. Furthermore, there is emerging evidence that AKI episodes can lead to Chronic Kidney Disease (CKD) accelerating the progression to End-Stage Renal Disease (ESRD) and contribute to higher long-term mortality risk. ${ }^{1}$

AKI represents a challenging clinical entity when it occurs during pregnancy. The worldwide incidence of Pregnancy-Related Acute Kidney Injury (PRAKI) has decreased markedly in the past 50 years through the legalization of abortion and improvement of antenatal and Obstetric care. In the recent years, the incidence of PRAKI has decreased in developed countries to only 1 to $2.8 \%$. However, PRAKI is still frequent in developing countries, the incidence is around 4.2-15\%. Caring for pregnant women diagnosed with AKI is a real challenge for obstetrician and the associated medical team. ${ }^{2}$

AKI is a clinical syndrome denoted by a decline in kidney function evidenced by increase in Serum Creatinine ( $\mathrm{SCr}$ ) and decrease in urine output. AKI is defined as an increase in SCr by $0.3 \mathrm{mg} / \mathrm{dl}(26.5 \mu \mathrm{mol} / \mathrm{l})$ within 48 hours or increase in SCr to1.5 times baseline, which is known or presumed to have occurred within the prior 7 days; or Urine volume of $<0.5 \mathrm{ml} / \mathrm{kg} / \mathrm{h}$ for 6 hours. ${ }^{3}$ Two recent and highly publicized consensus definitions and classification systems have been proposed (Acute kidney injury network \& RIFLE).

The acute dialysis quality initiative's RIFLE criteria stratified AKI into five groups: renal risk, renal injury, renal failure, renal loss, and ESRD. This classification has been proposed to allow consistency across studies for greater ability to compare clinical results.

Urine output reduction of less than $0.5 \mathrm{ml} / \mathrm{kg}$ per hour over the span of six hours was not specific enough to lead confidently to the designation of AKI. It was recognized that the hydration state, use of diuretics, and presence of obstruction could influence the urine volume, hence the need to consider the clinical context. Additionally, accurate measurements of urine output may not be easily available in all cases, particularly in patients in nonintensive care unit settings. Despite these limitations, it was felt that the use of changes in urine offers a sensitive and easily discernible means of identifying patients. ${ }^{6}$

Table 1: AKIN staging. ${ }^{4}$

\begin{tabular}{|llll|}
\hline $\begin{array}{l}\text { S. Cr (from } \\
\text { baseline) }\end{array}$ & $\uparrow$ Stage 1 & Stage 2 & Stage 3 \\
\hline $\begin{array}{l}\text { U.O.P } \\
(\mathrm{ml} / \mathrm{kg} / \text { hour })\end{array}$ & $\begin{array}{l}<0.5 \text { for } 6 \\
\text { hours }\end{array}$ & $\begin{array}{l}<0.5 \text { for } 12 \\
\text { hours }\end{array}$ & $\begin{array}{l}<0.3 \text { for } 24 \\
\text { hours/anuria } \\
\text { for } 12 \text { hours }\end{array}$ \\
\hline
\end{tabular}

Table 2: RIFLE criteria ${ }^{5}$ by acute dialysis quality initiative (ADQI).

\begin{tabular}{|llll|} 
& GFR & $\begin{array}{l}\text { Sr. Cr. } \\
\text { (from baseline) }\end{array}$ & $\begin{array}{l}\text { UOP } \\
\text { ( } \mathrm{ml} / \mathrm{kg} / \text { hour) }\end{array}$ \\
\hline Risk & $\downarrow>25 \%$ & $\uparrow>75 \%$ & $<0.5 \times 6$ hours \\
\hline Injury & $\downarrow>50 \%$ & $\uparrow>2$ times & $<0.5 \times 12$ hours \\
\hline Failure & $\downarrow>75 \%$ & $\uparrow>3$ times & $<0.3 \times 24$ hours \\
\hline Loss & $\begin{array}{l}\text { Persistent AKI }=\text { Complete loss of kidney } \\
\text { function for }>4 \text { weeks }\end{array}$ \\
\hline ESRD & \multicolumn{2}{l}{ End stage renal disease $>3$ months. }
\end{tabular}


AKI in pregnancy occurs between $35 \mathrm{wks}$ of pregnancy and puerperium primarily due to preeclampsia, Placental abruption \& other causes like Haemolytic Uremic Syndrome (HUS) and sepsis etc. Pregnancy associated Thrombotic Thrombocytopenic Purpura (TTP) and Acute Fatty Liver (AFL) of pregnancy are rare causes. Severe Pulmanary edema/Eclampsia/HELLP syndrome account for about $40 \%$ of cases of AKI in pregnancy. ${ }^{7}$ In pregnancy related AKIs Preeclampsia was seen in almost $38.3 \%$ of cases. ${ }^{8}$ In our case also severe Preeclampsia is found to be the causative factor.

For the purpose of diagnosis and management, AKI can be broadly divided into prerenal, intrarenal, and postrenal. ${ }^{9}$ The differential diagnosis of AKI is typically made in conjunction with the clinical history, physical examination findings, blood and urine laboratory values. Ultrasound of the urinary tract is useful to exclude postrenal AKI. Renal biopsy is reserved for patients in whom prerenal and postrenal AKI have been excluded and the cause of intrarenal AKI is unclear. It is also useful in cases in which clinical and laboratory assessment suggest diagnoses other than ischemic or nephrotoxic injury that may respond to disease-specific therapy. These conditions include glomerulonephritis, vasculitis, Hemolytic Uremic Syndrome (HUS), thrombotic thrombocytopenic purpura, and allergic interstitial nephritis. ${ }^{10}$

The assessment of patients with AKI requires a careful history, a thorough physical examination, and the judicious interpretation of laboratory data. Careful recording of remote and recent serum Creatinine levels over time, incorporating drug therapy and interventions is invaluable for differential diagnosis and for the identification of the possible cause of AKI. Thus with clinical evaluation \& investigations put together our case falls into the Stage 1 of AKIN or into the "RISK" category of "RIFLE" the cause being pre-renal.

Acute Kidney Injury (AKI) acquired is often due to a combination of insults. The most common associated causes are failure of renal autoregulation, direct nephrotoxicity, ischemia-reperfusion, and inflammatory state. On occasions, non-steroidal anti-inflammatory agents, used for postpartum analgesia, may precipitate AKI in patients who are volume depleted from hemorrhage, decreased fluid intake, or both.

Furthermore, AKI contributes to dysfunction of other organs, such as heart, lungs, brain, and liver.

Consequently, primary prevention and early diagnosis of AKI are of central clinical importance. So to say our case (Unbooked) of severe preeclampsia has resulted in PRAKI leading to $\uparrow S$. Cr. \& $\downarrow$ UOP thus emphasising the importance of early booking \& effective antenatal care to avoid the acute \& associated chronic kidney complications.
As per $\mathrm{KDIGO}^{3}$ (Kidney disease improving global outcomes) clinical practice guidelines for AKI being:

1. Evaluate patients with AKI promptly to determine the cause, with special attention to reversible causes.

2. Monitor patients with AKI with measurements of $\mathbf{S}$. Cr. and UOP to stage the severity.

3. Manage patients with AKI according to the stage and cause

4. Evaluate patients 3 months after AKI for resolution/new onset/worsening of pre-existing CKD.

Prevention, early recognition and prompt treatment is ideal. Using protocol-based management of hemodynamic and oxygenation parameters to prevent development or worsening of AKI in high-risk patients in the perioperative setting is mandatory. Avoiding nephrotoxic drugs, ensuring volume status/perfusion pressure, functional haemodynamic monitoring and monitoring of $\mathrm{Sr}$. $\mathrm{Cr}$. and $\mathrm{UOP}$ is a must. Isotonic crystalloids rather than colloids (albumin or starches) are as initial management for expansion of intravascular volume in patients at risk for AKI or with AKI. It is recommended not to use diuretics to prevent AKI and suggested not using diuretics to treat AKI, except in the management of volume overload. Diuretic use is often associated with deterioration in kidney function and should be stopped when feasible if AKI is attributed to prerenal causes. ${ }^{11}$

The relevance of albumin administration in the critical care setting remains controversial. It is known that Albumin has numerous important physiological effects and many potentially beneficial effects in critical illness. It is also known that hypoalbuminaemia is common in critically ill patients and is associated with worse outcomes. But routine administration of Albumin for fluid resuscitation is not warranted. Albumin may be useful in some patients, especially those with hypoalbuminaemia at risk of complications. ${ }^{12}$

In our case ample care was exercised in maintaining the intravascular volume and perfusion pressures using isotonic crystalloids initially. But due to severe oliguria not responding to this fluid regime and associated elevated Sr. Cr. and reduced Sr. albumin led to nephrologist's advice of human albumin infusion as chances of renal function improving with that cannot be ruled out.

With this simple medical means the patient's renal status could be improved considerably. Following one albumin infusion as patients could not afford for another unit of albumin, FFP infusions were advised instead as FFP is relatively cheap and an effective alternative which also fulfills the concept of fluid shift to intravascular compartment (5FFPs are equivalent to 1 human albumin). 


\section{CONCLUSION}

Acute kidney injury though rare, we do occasionally encounter these cases in obstetric population. Staging is very important in deciding the line of management. It is mandatory to treat these cases in the RISK stage itself before progressing to irreversible kidney damage. These cases if identified early with apt investigations and protocols can be treated with simple measures like human albumin and FFP infusions with a very good prognosis as in our case.

\section{Funding: No funding sources}

Conflict of interest: None declared

Ethical approval: Not required

\section{REFERENCES}

1. Macedo E, Bouchard J, Mehta RL. Renal recovery following acutekidney injury. Curr Opin Crit Care. 2008;14:660-5.

2. Mohamed Arrayhani, Randa El Youbi, Tarik Sqall. Pregnancy-Related acute kidney injury. ISRN Nephrol. 2013;2013:109034.

3. KDIGO. Clinical Practice guideline for acute kidney injury. Kidney Int Suppl. 2012;2:8-12.

4. José António Lopes, Sofia Jorge. The RIFLE and AKIN classifications for acute kidney injury: a critical and comprehensive review. Clin Kidney J. 2013;6(1):8-14.

5. Bellomo R, Ronco C, Kellum JA, Mehta RL, Palevsky P; Acute Dialysis Quality Initiative workgroup. Acute renal failure-definition, outcome measures, animal models, fluid therapy and information technology needs: the second international consensus conference of the Acute Dialysis Quality Initiative (ADQI) Group. Crit Care. 2004;8:R204-12.

6. Mehta RL, Kellum JA, Shah SV, Molitoris BA, Ronco C, Warnock DG, et al. Acute Kidney Injury Network: Report of an initiative to improve outcomes in acute kidney injury. Crit Care. 2007;11:R31.

7. S. Ananth Karumanchi, Phyllis August, Tiina Podymow. Renal complications in normal pregnancy. In: S. Ananth Karumanchi, Phyllis August, Tiina Podymow, eds. Comprehensive Clinical Nephrology. 4th ed. US: Mosby; 2010: 513514.

8. Prakash J. The kidney in pregnancy: a journey of three decades. Indian J Nephrol. 2012 MayJun;22(3):159-67.

9. Susana Machado, Nuno Figueiredo, Andreia Borges, Maria São José Pais, Luís Freitas, Paulo Moura, et al. Acute kidney injury in pregnancy: a clinical challenge. J Nephrol. 2012;25(01):19-30.

10. Didier Portilla, Sudhir V. Shah. Acute kidney injury. In: Didier Portilla, Sudhir V. Shah, eds. Andreoli and Carpenter's Cecil Essentials of Medicine. 8th ed. Philadelphia: Saunders; 2010: Chapter 32.

11. Etienne Macedo, Josée Bouchard, Ravindra L. Mehta. Prevention and nondialytic management of acute kidney injury. In: Etienne Macedo, Josée Bouchard, Ravindra L. Mehta, eds. Comprehensive Clinical Nephrology. 4th ed. US: Mosby; 2010: 835.

DOI: $10.5455 / 2320-1770 . \mathrm{ijr} \operatorname{cog} 20150442$

Cite this article as: Reddy KH, Praveen Kumar K, Rajan K, Shaik S. Pregnancy related acute kidney injury: nondialytic management. Int J Reprod Contracept Obstet Gynecol 2015;4:486-9. 